\title{
Clinical Trials in Neurovirology: Successes, Challenges, and Pitfalls
}

\author{
Dietrich Haubenberger ${ }^{1} \cdot$ David B. Clifford ${ }^{2}$
}

Published online: 18 May 2016

(C) The American Society for Experimental NeuroTherapeutics, Inc. (outside the U.S.) 2016

\begin{abstract}
Clinical trials in neurovirology illustrate the special challenges confronting investigators planning to study these conditions, as well as the contributions of successful trials in establishing appropriate management for these devastating diseases. This article reviews key examples of progress in neurovirology that have been spurred by clinical trials, emphasizing human herpes virus encephalitis, HIV, and JC virus. Clinical trials in the setting of neurovirological diseases are characterized by specific challenges, which may include small sample sizes, clinical presentations from life-threatening conditions to chronic courses of disease, regional and temporally restricted outbreaks scenarios, and the unavailability of validated diagnostic tests that can be rapidly deployed at the bedside. This review aims to highlight these methodological challenges and pitfalls in designing and executing clinical neurovirology trials, as well as to outline innovative trial designs, which could be useful in addressing common challenges.
\end{abstract}

Key Words Clinical trials · randomization · methodology · statistics $\cdot$ ethics

Dietrich Haubenberger

dietrich.haubenberger@nih.gov

1 Clinical Trials Unit, Office of the Clinical Director, NINDS Intramural Research Program, National Institutes of Health, 9000 Rockville Pike, Rm 6-5700, Bethesda, MD 20892, USA

2 Departments of Neurology and Medicine, Washington University in St Louis, Box 8111, 660 S Euclid Ave, Saint Louis, MO 63110, USA

\section{Introduction}

Steady progress in knowledge about the biology of viral disease of the nervous system, to which Dr. Richard Johnson contributed a great deal, has resulted in steady improvement in the treatment available for these diseases. However, translation of fundamental knowledge of viruses towards effective therapy for complex neurological disorders has been challenging, and remains a daunting enterprise. We will review key examples of progress in neurovirology that have been spurred by clinical trials, emphasizing fatal infections, including human herpes simplex virus (HSV) encephalitis, HIV, and JC virus (JCV). Clinical trials in these areas illustrate the special challenges confronting investigators, as well as the contributions of successful trials in establishing appropriate management for these devastating diseases. Building on the success and enlightenment of past trials, it is hoped that steady progress will be made to accelerate the diagnosis and development of effective therapy for many other virus-associated neurological conditions. It is the aim of this review to critically discuss examples of clinical trials in the field of neurovirology, focusing on methodological approach and trial design. Furthermore, this article aims to provide an overview of challenges and pitfalls in the planning and execution of clinical trials in the setting of neurovirology diseases, as well as outline novel methodological approaches in trial design.

\section{Methods}

The aim of this review is to highlight best-practice models for clinical trials in the field of treatment in neurovirological diseases, and outline common challenges, as well as provide an outlook on novel approaches in trial methodology. A PubMed search was performed to identify clinical trials in central nervous system (CNS) infections due to HIV, HSV, and JCV. 
Relevant articles were further screened in a nonsystematic fashion with the goal of identifying trials based on their generalizability to the broader field of neurovirology, in particular whether a trial was conducted with a clinical neurological outcome, was conducted in a prospective fashion, and was aimed at treating the underlying neurovirological disease. Clinical trials on preventative approaches, including vaccines and treatments of peripheral nervous system symptoms (e.g., neuropathies), as well as supportive or nonpharmacological treatments, were considered beyond the scope of this article. This review was focused on the most intensely studied viral CNS infections due to HIV, HSV, and JCV, as these diseases represent fatal viral infections for which a critical number of clinical trials fulfilling these criteria were available. In the discussion about common challenges, other indications were also selected to highlight the uniqueness of the individual disease settings (e.g., emerging infection scenario of Ebola). Publications of clinical trial results, as well as clinical trial protocols, were considered for this review, while the trial designs were not limited to randomized controlled trials (RCTs), and results could be either positive or negative, as long as relevant information could be extracted to inform future clinical trials in the field.

\section{Herpes Simplex Encephalitis}

HSV encephalitis (HSVE) is the most common nonepidemic form of viral encephalitis. Prior to development of modern therapy, outcomes were generally very poor, with the majority of patients dying, and the survivors often suffering devastating brain injury. It is now recognized that early treatment with aciclovir improve outcomes, although even today patients developing this dangerous encephalitis often risk serious brain damage or death. Starting in the 1960s it was recognized that it should be possible to interrupt viral replication, and observations from a series of case reports suggested activity for idoxuridine. A critically important step in therapeutics was organization of multicenter clinical trial groups capable of enrolling the rare patients for prospective clinical trials. Table 1 shows key clinical trials leading to current standards of care for HSVE. By 1975, the first of these efforts quickly ended use of idoxuridine when a small, prospective, placebocontrolled study clearly demonstrated that idoxuridine had an unfavorable efficacy to toxicity ratio [1]. Subsequent research turned to vidarabine, which proved to have benefit when compared with placebo [2]. However, the still poor outcomes stimulated ongoing research, with 2 major comparative studies between vidarabine and aciclovir, and both demonstrating clear superiority of aciclovir $[3,4]$. This has remained the standard of care over the last 30 years.

Development of HSV therapy was bolstered by several critical areas of scientific progress that are mirrored with other viral diseases. Rapid and safe diagnosis is critical for clinical trials. Only if the study sample has the condition studied at a stage where irreparable brain damage has not yet occurred can one hope to test therapeutics. The early trials for HSV were challenged by requiring brain biopsy diagnosis in cases where a clinically suspect patient was considered for the trial [1-3]. In spite of the complexity and risk of brain biopsy, without an alternative secure means of diagnosis, it was necessary because clinical diagnosis was only correct in roughly half of cases. Use of brain biopsy assured that drugs were tested only in appropriate patients, while also refining clinical diagnosis by discovering mimics of HSV that would not have benefited the trial intervention [5]. The value of biopsy validated cerebrospinal fluid (CSF) samples from these trials was further leveraged by subsequent development of polymerase chain reaction (PCR) detection of HSV DNA using CSF samples collected from these established cases [6, 7]. Advances in imaging also enhanced clinical trials. The development first of computed tomography brain imaging in the 1970s and more sensitive magnetic resonance brain imaging in the 1980s has provided critical diagnostic information facilitating early diagnosis and therapy.

Table 1 Clinical trials in herpes simplex virus (HSV) encephalitis

\begin{tabular}{|c|c|c|c|c|c|c|c|}
\hline Year & $\begin{array}{l}\text { Intervention/ } \\
\text { arms }\end{array}$ & $n$ & Diagnostic criteria & Primary end point & Key observations & Outcomes & Ref. \\
\hline 1975 & Idoxuridine & 12 & Brain $\mathrm{Bx} /$ culture & Death & Serious hematologic toxicity & No survival advantage & {$[1]$} \\
\hline 1977 & $\begin{array}{l}\text { Vidarabine/ } \\
\text { placebo }\end{array}$ & 28 & Brain $\mathrm{Bx} /$ culture & Death & $\begin{array}{l}\text { Baseline status critical to outcomes } \\
\text { /functional status outcome }\end{array}$ & Reduced mortality & {$[2]$} \\
\hline 1984 & $\begin{array}{l}\text { Vidarabine (V)/ } \\
\text { aciclovir (A) }\end{array}$ & $\begin{array}{r}127 \text { (53 HSV } \\
\text { confirmed) }\end{array}$ & $\begin{array}{c}\text { Brain } \mathrm{Bx} / \mathrm{and} / \text { or serum } \\
\text { and CSF antibody }\end{array}$ & $\begin{array}{c}\text { Death: V } 50 \% \\
\text { vs A } 19 \%\end{array}$ & $\begin{array}{l}\text { Normal function at } 6 \text { months } \\
\text { favored aciclovir/ }\end{array}$ & $\begin{array}{l}\text { Reduced mortality } \\
\text { and morbidity } \\
\text { with aciclovir }\end{array}$ & [4] \\
\hline 1986 & $\begin{array}{r}\text { Vidarabine (V)/ } \\
\text { acyclovir (A) }\end{array}$ & $\begin{array}{r}208 \text { (69 HSV } \\
\text { confirmed) }\end{array}$ & Brain $\mathrm{Bx}$ & $\begin{array}{c}\text { Death: V } 54 \% \\
\text { vs A } 28 \%\end{array}$ & $\begin{array}{l}\text { Functional outcome, as well } \\
\text { as death, significant; } \\
\text { sensitivity analysis by } \\
\text { baseline function/ } \\
\text { age impact on outcome }\end{array}$ & $\begin{array}{l}\text { Aciclovir superior } \\
\text { to vidarabine }\end{array}$ & [3] \\
\hline
\end{tabular}

$\mathrm{Bx}=$ biopsy, $\mathrm{CSF}=$ cerebrospinal fluid 
HSV clinical trials also critically supported a key principle that early treatment is essential for good outcomes. Irreparable HSV-induced hemorrhagic and necrotic brain lesions in the trials were only prevented with early intervention [2]. Current practice is guided by aciclovir's well-known safety profile, which is compatible with transient dosing of patients who ultimately do not have HSV to accrue substantially better outcomes in the minority that eventually are found to have the disease. Because of the high degree of sensitivity and specificity for HSV PCR detection in cases, failure of HSV DNA detection supports discontinuation of therapy in low-risk patients (negative imaging, absence of CSF pleocytosis) $72 \mathrm{~h}$ after onset of disease. However, equivocal diagnostic findings that are not explained by another condition may merit a full 14-day course of aciclovir $[8,9]$.

It is striking that in HSVE, which still has a mortality approaching $30 \%$ and causes serious brain damage, there have been no significant enhancements of therapy in the last 30 years [10]. Factors contributing to this include the rarity and sporadic nature of the diagnosis, leading to clinical trials being complex and costly. Topics that would require further clinical trials include the possible contribution of corticosteroids, alternate drugs (including oral antiherpes drugs) and the evaluation of the optimal duration of therapy [11].

\section{HIV-associated Neurocognitive Disorder}

HIV emerged in the 1980s as a major cause for neurological diseases, becoming a critical therapeutic target. Some of the conditions that emerged were characteristic opportunistic neurological infections such as toxoplasma encephalitis, cryptococcal meningitis, cytomegalovirus encephalitis, and progressive multifocal leukoencephalopathy, all emerging from chronic cellular immunodeficiency in AIDS [12]. However, it was soon apparent that HIV itself entered the CNS early, and as the disease advanced, untreated HIV commonly progressed to cause an HIV-associated dementia (HAD) that was generally fatal in less than a year from symptomatic onset $[13,14]$.

HIV-associated neurocognitive disorder (HAND), ranging from the disabling HAD to asymptomatic suboptimal performance on neuropsychometric testing, was rarely the focus of organized neurology-specific clinical trials. Most of the evidence of neurological efficacy of HIV therapy came from observation of patient cohorts in systemic disease trials. Optimizing antiviral therapy for HAND has been limited by the modest investment in clinical trials specifically focusing on CNS infection and neurocognitive impact of the therapies (Table 2). From the earliest studies, it was noted that zidovudine, the first drug tested for treatment of HIV, resulted in symptomatic improvement (e.g., weight loss, diarrhea, reduced opportunistic disease) in patients with advanced AIDS, and improved neurocognitive performance. Improved neurocognitive performance was demonstrated in advanced patients during the first 16 weeks of therapy [15]. This observation was confirmed by the only placebo-controlled trial in patients selected for dementia, where very high doses of zidovudine improved neuropsychometric performance, and was repeated as didanosine was introduced $[16,17]$. The impact of combining nucleosides soon followed, as it became clear that the rapid evolution of resistant virus shortened the duration of response to monotherapy. Two studies using add-on neurocognitive testing demonstrated the positive impact of combination therapy in sustaining neurocognitive benefit $[18,19]$. However, neurological testing is often limited in these studies because of fear that burdensome neuropsychological batteries and CSF sampling will discourage enrollment and retention required for the nonneurological primary end points.

Selection of neurological end points has also been challenging. Virus invasion in brain cannot be directly measured in trials, and the quantification of CSF HIV RNA, which is seen as a flawed surrogate, has been challenging because patients and investigators both find this procedure daunting. Efforts to reassure patients that this is a safe and tolerable procedure have only been partially successful. While higher CSF viral loads were associated with more severe HAND, and the goal of eliminating HIV from the CSF seemed a plausible target, it was obvious that its CSF markers were only an imperfect reflection of the impact of HIV on brain performance [20,21]. Neurocognitive performance is a valuable neurological end point and has become the typical end point for neurological studies. However, the nonspecific characteristics of these measurements, performed without the benefit of knowing the level of premorbid performance, affected by a multitude of confounding behavioral factors, and poorly associated with the current activity of virus in the brain, remains a challenging aspect of this research. Alternative biomarkers of CNS disease have been sought. CSF measures reflecting inflammatory disease in the brain appear promising, and are clearly associated with active viral disease, but are less robust in the light of more subtle, potentially smoldering HAND. Also, serum markers for CNS disease have been studied, but the leading candidates, including CD163 and HIV DNA in CD14+ cells, have not been proven as useful in clinical trials $[22,23]$.

Ongoing cognitive impairment, occasional episodes of viral replication developing in the brain (termed CSF viral escape), and evidence of ongoing inflammatory responses in the brain compartment reflected in CSF continue to support trials targeting CNS HIV complications [24-26]. The target of curing HIV must include the brain reservoir of virus, which is likely to be one of the most challenging targets for this agenda, because of the unique environment of the brain.

One of the most attractive hypotheses has been that penetration of antiviral agents into brain is suboptimal, resulting in ongoing viral replication. A framework for testing this hypothesis was created through categorizing available HIV drugs 
Table 2 HIV-associated neurocognitive disorder (HAND) antiviral trials

\begin{tabular}{|c|c|c|c|c|c|c|c|c|}
\hline Year & Intervention/arms & $n$ & Diagnostic criteria & $\begin{array}{l}\text { Therapy } \\
\text { duration }\end{array}$ & $\begin{array}{l}\text { Primary end } \\
\text { point }\end{array}$ & Key observations & Outcomes & Reference \\
\hline 1988 & ZDV/placebo & 281 & AIDS/ARC & 16 weeks & $\begin{array}{l}\mathrm{NP} \\
\quad \text { performance }\end{array}$ & $\begin{array}{l}\text { AIDS patients } \\
\text { improved NP/affective } \\
\text { measures stable }\end{array}$ & ZDV improved NP & {$[15]$} \\
\hline 1993 & $\begin{array}{l}\text { ZDV } 1000 \mathrm{mg} / \text { day, } \\
\text { ZDV } 2000 \mathrm{mg} \text { /day vs } \\
\text { placebo, ZDV after } \\
16 \text { weeks in placebo }\end{array}$ & 40 & $\begin{array}{l}\text { AIDS dementia } \\
\text { complex } \\
\text { (mild/moderate) }\end{array}$ & 16 weeks & $\begin{array}{l}\text { NPZ-7 (NP } \\
\text { tests) }\end{array}$ & $\begin{array}{l}\text { Statistically significant } \\
\text { improvement in } \\
\text { high-dose arm }\end{array}$ & $\begin{array}{l}\text { ZDV active } \\
\text { against HAD }\end{array}$ & [16] \\
\hline 1997 & $\begin{array}{l}\mathrm{DDI} / 500 \mathrm{mg} v s \\
\mathrm{DDI} / 750 \mathrm{mg} v s \mathrm{ZDV}\end{array}$ & 107 & AIDS/ARC patients & 12 months & NPZ-7 & $\begin{array}{l}\text { Piggyback design } \\
\text { study with NP on } \\
\text { subset of randomized } \\
\text { study }\end{array}$ & $\begin{array}{l}\text { Stable NP function } \\
\text { maintained by DDI, } \\
\text { consistent with ZDV }\end{array}$ & {$[17]$} \\
\hline 1999 & $\begin{array}{l}\text { ZDV alternating/DDI or } \\
\text { DDC, ZDV/DDI, } \\
\text { ZDV/DDI/nevirapine }\end{array}$ & 1313 & AIDS $(\mathrm{CD} 4<50)$ & 52 weeks & NPZ-4 & $\begin{array}{l}\text { Poor NP outcome } \\
\text { associated with } \\
\text { mortality }\end{array}$ & $\begin{array}{l}\text { Combination therapy } \\
\text { superior to alternating } \\
\text { monotherapy }\end{array}$ & [19] \\
\hline 2001 & $\begin{array}{l}\mathrm{ABC} / \text { placebo }+ \text { stable } \\
\text { background therapy }\end{array}$ & 105 & $\begin{array}{l}\text { AIDS dementia } \\
\text { complex }\end{array}$ & 12 weeks & $\begin{array}{l}\text { NPZ } \\
\quad \text { change }\end{array}$ & $\begin{array}{l}\text { CSF virology and } \\
\text { cytokines/importance } \\
\text { of stable background } \\
\text { therapy/need to } \\
\text { minimize practice } \\
\text { effect with NP }\end{array}$ & No benefit from $\mathrm{ABC}$ & {$[30]$} \\
\hline 2007 & $\begin{array}{l}\text { New cART, prospective } \\
\text { start of cART or change, } \\
\text { ACTG } 736 \text { Study }\end{array}$ & 101 & $\begin{array}{l}\text { Advanced HIV } \\
\text { starting new } \\
\text { cART regimen }\end{array}$ & $\begin{array}{c}24 \text { and } 48 \\
\text { weeks }\end{array}$ & $\begin{array}{l}\text { CSF HIV } \\
\text { RNA }\end{array}$ & $\begin{array}{l}\text { Higher CPE associated } \\
\text { with worse NP } \\
\text { performance }\end{array}$ & $\begin{array}{l}\text { Higher CPE } \\
\text { associated } \\
\text { with CSF viral control }\end{array}$ & {$[34]$} \\
\hline 2013 & $\begin{array}{l}\text { Randomized CNS } \\
\text { targeted } v s \text { nontargeted } \\
\text { therapy }\end{array}$ & 49 & HAND & 16 weeks & GDS change & & $\begin{array}{l}\text { No cognitive benefit } \\
\text { of CNS-targeted } \\
\text { therapy }\end{array}$ & {$[28]$} \\
\hline 2015 & $\begin{array}{l}\text { Maraviroc intensification } \\
\text { on stable ART with } \\
\text { viral control/open- } \\
\text { label, randomized } \\
\text { control }\end{array}$ & 14 & HAND & $\begin{array}{l}6 \text { and } 12 \\
\text { months }\end{array}$ & GDS/MRS & $\begin{array}{l}\text { Stabilized metabolic } \\
\text { status compared } \\
\text { with controls }\end{array}$ & $\begin{array}{l}\text { Trend to improved NP } \\
\text { over } 12 \text { months }\end{array}$ & {$[32]$} \\
\hline
\end{tabular}

$\mathrm{ZDV}=$ zidovudine; $\mathrm{ARC}=$ AIDS-related complex; $\mathrm{NP}=$ neuropsychological; $\mathrm{NPZ}=$ neuropsychological $\mathrm{Z}$ score; $\mathrm{DDI}=$ didanosine; $\mathrm{DDC}=$ zalcitabine; $\mathrm{ABC}=$ abacavir; $\mathrm{CSF}=$ cerebrospinal fluid; $\mathrm{cART}=$ combined antiretroviral therapy; $\mathrm{CPE}=$ central nervous system penetration effectiveness; GDS = global deficit score; MRS = magnetic resonance spectroscopy; HAD = HIV associated dementia

according to best evidence and theoretical constructs as to their ability to enter the brain. A clinical penetration effectiveness (CPE) score summing categorization of drugs used in a patient provided a measure to compare virological and clinical status according to predicted CPE. Cross-sectional studies suggested that this score might reliably reflect risk of viral detection in the CSF, but the correlation with neurocognitive performance remained unanswered [27]. A prospective study designed to test CPE directly proved very challenging to accrue and did not have reliable power for detection of the clinical impact of highly penetrating therapy [28]. The most recent efforts to address persisting HAND with antiviral therapy have sought to enhance therapy by addition of more drugs, generally with additional mechanisms of action. When abacavir was introduced, it was hypothesized that it might be a superior nucleoside therapy for the brain, and a study focusing on dementia as an outcome was initiated $[29,30]$. To date, no convincing evidence is available that intensification of antiviral therapy will successfully address persisting cognitive impairment in otherwise successfully treated patients $[31,32]$. A theoretical concern that blunts enthusiasm for intensification strategies is the possibility of medication associated toxicity to the CNS [33]. The idea that some antivirals are neurotoxic, and that high $\mathrm{CPE}$ might increase toxicity, remains a consideration in therapeutic development [34].

In spite of these challenges, combination antiretroviral therapy has transformed the prognosis for patients with HIV [35, 36]. Opportunistic brain infections have vastly decreased, and this therapy has resulted in almost complete elimination of HIVassociated dementia. The majority of patients with residual HAND are asymptomatic or have mild disability that is not progressing over the timeframe of observation in the majority of patients [37, 38]. In the absence of improved markers of residual virus in the brain, antiviral studies are difficult to design. An emerging focus, shared with all HIV therapeutics, is the impact of earlier treatment initiation on developing HAND. Owing to cost and toxicity of therapy, HIV treatments were withheld until substantial immunodeficiency developed in the early years of the epidemic. With improved therapy, the principle of importance of early therapy has emerged in HIV treatment. Evidence of viral-driven neurotoxicity, even in the earliest days of HIV infection, suggests that there may be substantial value in starting therapy early $[39,40]$. As expert consensus has 
rapidly moved toward early diagnosis and therapy, careful assessment of outcomes from early therapy are eagerly awaited in hopes that this approach may prevent brain injury by HIV.

Efforts to inhibit downstream neurotoxic mechanisms of HIV infection have been a major focus of RCTs directed at HAND. At most, these have been phase 2 randomized trials, powered for safety but insufficient to inform efficacy reliably. Mechanisms addressed include peptide T with gp120 neurotoxicity-blocking properties [41], antioxidants [42], antiapoptotic mechanisms [43], calcium channel antagonists [44], platelet-activating factor antagonists [45], $N$-methyl-Daspartate antagonists [44], p38 mitogen-activated protein kinase antagonists [44], anticholinesterase [46] and antiinflammatory drugs [47]. The duration of these trials has generally been limited to $12-24$ weeks, and as placebo-treated arms rarely deteriorate, hopes for evidence of efficacy hinge on restoration of brain function, an end point that may be difficult to achieve if brain damage has already occurred.

\section{Progressive Multifocal Leukencephalopathy}

When considering serious virological diseases of the brain for which therapies are desperately needed, progressive multifocal leukencephalopathy (PML) has received much attention in recent years. This statement would have shocked neurologists of 40 years ago, as JCV, the etiologic DNA virus causing PML, has virtually no clinical correlate in healthy people, and as its initial description was an exceedingly rare complication primarily associated with hematologic malignancy. All that changed with the HIV pandemic, where a large population of chronically cell-mediated immunosuppressed patients was found to die frequently from PML. In the era before HIV therapy was available, as many as $5 \%$ of all AIDS deaths were associated with PML [48]. Death within a few months of symptomatic onset of disease was the usual outcome of PML. Case reports, and theoretical considerations about the pathophysiology of JCV, led to several clinical trials (Table 3). One of the most decisive trials tested adding cytarabine, administered either intravenously or intrathecally, compared with the best antiviral HIV therapy alone [49]. This randomized trial of 57 patients with PML with verified diagnosis via brain biopsy demonstrated no benefit from cytarabine on the rapid progression of patients toward death. This trial was conducted before the introduction of combined antiretroviral therapy (cART). A subsequent trial tested the topoisomerase inhibitor topotecan, which proved toxic with minimal activity resulting in discontinuation of the trial after accrual of only 12 patients [50]. Subsequently, cidofovir therapy was tested in a phase 1-2 open-label trial with 24 patients, but did not improve the survival as seen with the use of cART [51]. Cidofovir outcomes were combined with several observational cohorts in a careful meta-analysis that confirmed no efficacy on mortality or morbidity using cidofovir [52]. As marked improvement of survival has been seen since the introduction of cART, assessing the effects of cART on the most important outcomes has been pursued. One such study prospectively followed 28 patients, who were started on a 5-drug cART regimen, including enfuvirtide, for a period of 6 months. Survival was $81 \%$ at 6 months, and was associated with robust recovery of anti-JCV T-cell responses and JCV clearance from CSF [53]. While this outcome is the best reported for HIV, it is difficult to speculate the value of the specific enhanced therapy without a contemporary control arm. Survival in a recent trial in patients with HIV was similar without an intensified cART regimen [54].

Table 3 Progressive multifocal leukoencephalopathy (PML) clinical trials

\begin{tabular}{|c|c|c|c|c|c|c|c|}
\hline Year & Intervention/arms & $n$ & Diagnostic criteria & Primary end point & Key observations & Outcomes & Reference \\
\hline 1998 & $\begin{array}{l}\text { HIV dual } \\
\text { nucleoside/+ } \\
\text { cytarabine i.v./+ } \\
\text { cytarabine i.t. }\end{array}$ & 57 & Brain biopsy & Survival & $\begin{array}{l}\text { Viral titer in CSF correlates } \\
\text { with survival [82] }\end{array}$ & $\begin{array}{l}\text { Cytarabine fails to } \\
\text { improve survival } \\
\text { outcome in HIV- } \\
\text { associated PML }\end{array}$ & [49] \\
\hline 2003 & $\begin{array}{l}\text { Topotecan } \\
\quad \text { immediate } v s \\
\text { delayed }\end{array}$ & 12 & $\begin{array}{l}\text { Brain biopsy/or } \\
\text { JC DNA in CSF }\end{array}$ & $\begin{array}{l}\text { Safety, Kurtzke } \\
\text { progression }\end{array}$ & $\begin{array}{l}\text { Significant toxicity, } \\
\text { less severely affected } \\
\text { patients more likely } \\
\text { to survive }\end{array}$ & $\begin{array}{l}\text { Topoisomerase } \\
\text { inhibitors } \\
\text { abandoned }\end{array}$ & {$[50]$} \\
\hline 2002 & $\begin{array}{l}\text { Cidofovir i.v. }+ \\
\text { cART }\end{array}$ & 24 & $\begin{array}{l}\text { MRI/CSF PCR/ } \\
\text { clinical or brain } \\
\text { biopsy }\end{array}$ & $\begin{array}{l}\text { Safety, tolerability, } \\
\text { effect CDV at } 24 \\
\text { weeks }\end{array}$ & $\begin{array}{l}\text { Clinical outcome best when } \\
\text { HIV viral load controlled } \\
\text { at baseline }\end{array}$ & $\begin{array}{l}\text { Cidofovir failed to } \\
\text { improve clinical } \\
\text { outcome }\end{array}$ & {$[83]$} \\
\hline 2011 & $\begin{array}{l}\text { Enfuvirtide- } \\
\text { enhanced } \\
\text { HIV therapy }\end{array}$ & 28 & MRI/CSF PCR & $\begin{array}{l}\text { Survival, } 6 \text { and } \\
12 \text { months }\end{array}$ & $\begin{array}{l}\text { Marked recovery of JCV- } \\
\text { specific T cells, CSF } \\
\text { JCV DNA cleared from } \\
\text { CSF }\end{array}$ & $\begin{array}{l}75 \% \text { survival for } 1 \\
\text { year }\end{array}$ & {$[53]$} \\
\hline 2013 & Mefloquine & 37 & MRI/CSF PCR & $\begin{array}{l}\text { 4- and 8-week JCV } \\
\text { viral load decline }\end{array}$ & $\begin{array}{c}\text { Early decline in CSF JC viral } \\
\text { load at } 4 \text { weeks predicted } \\
\text { better } 16 \text {-week outcome }\end{array}$ & $\begin{array}{l}\text { No mefloquine } \\
\text { related effect } \\
\text { on JCV, safe }\end{array}$ & {$[54]$} \\
\hline
\end{tabular}

$\mathrm{CSF}=$ cerebrospinal fluid; $\mathrm{cART}=$ combined antiretroviral therapy; $\mathrm{MRI}=$ magnetic resonance image $\mathrm{PCR}=$ polymerase chain reaction; $\mathrm{CDV}=$ cidofovir; JCV $=\mathrm{JC}$ virus 
Seeking alternative antiviral drugs to address JCV has been attempted by using a high-throughput screening approach of approved drugs. Mefloquine, a well-known antimalarial therapy, showed potential in this in vitro screen [55]. As it was known to reach presumed therapeutic concentrations in brain and has a reasonable safety profile, an international randomized study to treat PML was undertaken. Given the already considerably reduced mortality and morbidity of PML with the use of cART, the target of this trial was the rate of reduction of CSF JCV DNA levels with mefloquine-enhanced standard of care therapy versus the standard of care alone. An international network struggled to accrue 37 patients to this study, which was terminated when an interim analysis suggested futility. The trial revealed no clear benefit of the intervention for mortality, morbidity, or clearing of JC DNA from the CSF [54]. It was observed that an early decline in CSF JC DNA during the first 4 weeks of therapy was predictive of a better outcome after 16 weeks.

This trial illustrates many of the challenges of mounting antiviral therapy for brain disorders. With mortality significantly $<$ $50 \%$, end points for survival take many more patients to reach statistical significance, while the number of available patients is steadily declining as HIV care is initiated earlier. To date, no RCT for PML has reached the target enrollment, so power of all trials is less than intended owing to challenges in recruitment. Competition of other safe and available unproven therapies taints trial design and inhibits interest in trials. Mefloquine could be prescribed by any physician with relative safety and ease, negatively affecting recruitment efforts. Owing to this, the study was amended to allow switching over to active treatment as early as 4 weeks postrandomization in the standard of care arm limiting the duration to control for the intervention drug effect. Survival of the patients with HIV was high in this trial, and most survivors ultimately received the intervention. Ultimately, it was impossible to demonstrate clearly any contribution of mefloquine.

Thus, therapy for JCV itself has not advanced, despite multiple clinical trial efforts. However, the process of immune reconstitution has amply demonstrated efficacy in mitigating PML prognosis $[53,56]$. Immune reconstitution as an effective approach to control of PML has been further established by the important experience of treating PML associated with natalizumab therapy in the setting of multiple sclerosis. Natalizumab-associated PML emerged in 2005 when this effective integrin inhibitor was found to increase vastly the risk of developing PML in a population that had previously never seen this complication [57-60]. Rapid immune reconstitution can be accomplished by using plasma exchange to speed drug clearance and allowing access to the brain for the existing immune response. While $\sim 20-30 \%$ of patients still die, the majority survive with variable degrees of brain injury depending on the location of lesions (https://medinfo.biogen.com/ secure/pmlresource). It seems that in any setting in which PML develops, efforts to enhance immune responses are beneficial. The latest efforts enhance this strategy include the use of recombinant interleukin-7 and sometimes VP1 protein vaccination to augment immune responses to JCV [61, 62].

It should be noted that events of immune reconstitution may confound the interpretation of other potential biomarkers for JCV activity. Magnetic resonance fluid-attenuated inversion recovery images (MRI FLAIR) dramatically demonstrate lesions in the brains of patients with PML. Magnetic resonance imaging (MRI) brain lesions often substantially enlarge during immune reconstitution inflammatory syndrome, suggesting an almost inverse relationship between image severity and ultimate clinical outcomes Clinical deterioration often transiently accelerates as immune reconstitution expands lesions, but this enhanced brain dysfunction is more reversible than the lytic viral lesions experienced in the absence of immune response. Consequently, it is important to support patients through the immune reconstitution phase. This course also means that clinical trials seeking to measure outcomes in PML should likely be extended to at least 12 months to achieve JCV control (which largely occurs in the first months), as well as recovery from the immune reconstitution inflammatory syndrome response, which continues past 6 months.

The experience with PML trials recapitulates observations associated with HSVE. Diagnosis in early trials depended on brain biopsy, which often delayed initiation of therapy, and had its own morbidity and mortality. The combination of MRI lesion detection and CSF demonstration of virus with PCR technology permits sensitive, rapid, and less invasive diagnosis, and better outcomes [63]. However, the challenges of RCTs of PML are daunting. The disease is already rare and appears likely to decline with earlier HIV therapy. Cases remain disseminated geographically. The rapidity and severity with which PML strikes makes transporting patients to distant centers unsafe and unattractive to families, further inhibiting the close management that would be ideal for trials for a serious subacute neurological condition. Delay in treatment is likely to result in poorer outcomes, and crossover designs that might optimize the information extracted from small number of patients are unlikely to be reliable given rapid progression with permanent brain injury associated with PML. Development of in vitro systems for replicating JCV biology, as well as animal models for this uniquely human adapted virus, may help identify more effective treatment strategies. These could be applied to patients with the worst prognosis to identify potential antiviral efficacy. Patients with hematologic malignancy and organ transplantation, while rare, may represent a suitable population to examine interventions, as without intervention they continue to have the most dire prognosis [64].

\section{Common Challenges}

\section{Randomization, Controls, and Equipoise}

As shown in the example of idoxuridine in the treatment of HSVE, selective reporting of case and small series can be 
hypothesis generating, but it is critical to maintain healthy skepticism, as harmful therapy can still be perpetuated through case reports and uncontrolled case series. RCTs are considered the gold standard in providing unbiased data on a novel treatment intervention. To justify ethically a comparison to a standard treatment, equipoise needs to be present towards the novel treatment. Controversies around the applicability of randomization stem from situations where preliminary data suggests a new treatment being significantly more effective than the standard treatment [65]. However, preliminary data from smaller preceding clinical trials rarely provide reliable effect size estimates [66], and therefore cannot give sufficient evidence against clinical equipoise. Following the experiences with the early clinical trials during the HIV/AIDS pandemic in the 1980s, a controversy erupted over whether in the absence of a standard treatment all patients should receive immediate access to study treatment, with only a remote chance of improvement. In situations where randomized, placebo-controlled trials are difficult to execute, alternative control strategies include active treatment controlled trials, no treatment controlled trials, dose comparison controlled trials, and externally controlled trials. Byar et al. [67] argued that under certain instances, an "uncontrolled" trial may be justified: 1) no other treatment is appropriate as a control, 2) the patients not receiving therapy will have a uniformly poor prognosis, 3) the therapy does not have substantial side effects that would compromise the potential benefit to the patient, 4) there is a justifiable expectation that the potential benefit to the patient will be sufficiently large to make interpretation of the results of a nonrandomized trial unambiguous, and 5) the scientific rationale for the treatment must be sufficiently strong that a positive result would be widely accepted [67]. However, it can be argued that even under these circumstances where a concurrent control arm is not feasible, a best possible level of external controlling should be achieved. In particular, baseline controlled trials, or the use of historical controls, may be helpful in this scenario. The conditions to improve acceptability of historical controls include the requirement that a historical control arm should receive the same background standard treatment, should be part of a recent clinical trial with the same eligibility criteria, exhibit a similar distribution of important patient characteristics, and be evaluated using the same methods as the experimental treatment arm [68]. The 2 main concerns with historical controls are 1) that important prognostic covariates, both measured and not measured, are often imbalanced compared with the treatment group, and that 2) supportive and concomitant care may change over time, making a comparison challenging [69].

Given the broad limits of interpretability of nonrandomized trials, randomization greatly reduces the risk of reaching erroneous conclusions with false-negative findings leading to abandoning of lifesaving measures, or false-positive conclusions resulting in the use of ineffective treatment [69]. Approaches to improve acceptability of placebo arms would be preplanned interim analyses for early termination of a trial should the predefined boundaries for efficacy or safety be crossed, with a subsequent open-label phase where patients randomized to placebo my receive active treatment.

\section{Clinical Trials in an Outbreak Setting}

Outbreaks of infectious diseases present several difficulties to clinical trials planning: nonendemic outbreaks are typically regionally and temporally circumscribed and unpredictable, challenging medical staff, infrastructure, and policy-makers and the media. The experiences from the HIV/AIDS epidemic demonstrated that an environment allowing the rigorous evaluation of potential treatments is dependent on an extensive dialogue between affected communities, scientists, and regulatory agencies. Emanuel et al. [70] (adapted by Lane et al. [71]) formulated core ethical and scientific principles for trial conduct in an outbreak setting in developing countries: 1) ethical conduct to avoid exploitation, including respect for volunteers, local community engagement, and carefully informed consent involving the community to establish recruitment procedures and incentives; 2) partnership with investigators and officials in affected countries, including the identification of interested local investigators, strengthen the local trial infrastructure, and shared best practices of regulator oversight; 3 ) scientific validity, including a favorable risk-benefit ratio to the study population and sound trial design; 4) independent review and scientific oversight, ensuring public accountability through transparency and mandated reviews, including the oversight of an independent and skilled Data and Safety Monitoring Board; and 5) transparency, including the prompt sharing of data with practitioners and affected communities. To improve clinical trial "readiness" in outbreak settings, prospective planning may include the installation of clinical trial networks, centralized institutional review board approvals [72], as well as novel trial designs such as platform trials, which allow a rapid implementation of therapies once they become available [73].

\section{Rare Disease Setting}

Many neurovirological diseases typically present with a low prevalence, fulfilling the criteria of rare diseases, that is, $<200$, 000 cases at any given time in the USA. Clinical trials in the rare disease setting are often challenging, as limited sample sizes may restrict the ability to design a clinical trial with adequate statistical power. Clinical trials on limited numbers of available participants ("small clinical trials") should be planned under similar scrutiny as large clinical trials [74]. Enrichment strategies, such as multisite approaches, as well as innovative trial designs, such as adaptive and sequential trial designs, may overcome these limitations of small trials, maximizing the information to be drawn from small sample sizes. Sequential study designs allow subjects or groups of subjects to be enrolled into a trial in a sequential 
manner: where the "rules" change, for example for treatment allocation, the more information is required. A sequential design can follow predefined decision steps or be based on a Bayesian approach of defining prior probabilities, which are adjusted the more information comes in. Sequential designs, such as the Bayesian continuous reassessment method, are particularly useful during dose-escalation and dose-finding trials in planning sample sized most efficiently in this critical trial phase [75]. In adaptive designs, trial characteristics are modified based on incoming accumulating information. Bayesian-based adaptive designs allow more flexibility than traditionally designed trials, in particular in terms of sample size re-estimations at critical time points during the trial, as well as to decide whether treatment arms should be dropped or continued into a next stage of a trial, which could be then a confirmatory phase [76].

\section{Diagnostic Tests and Outcome Measures}

Especially in an emergent disease outbreak or otherwise acute setting involving unique organisms, it is central to be able to distinguish rapidly and reliably between subjects carrying the disease and subjects with other diseases. Diagnostic tests such as antigen detection tests can act as inclusion criterion to prove absence or presence of the infection to be targeted, and also may serve as surrogate measure for treatment response. However, sensitive and specific assays, which can be deployed rapidly, are often not available at the time of outbreak, when clinical trials are being initiated. While quantitative methods may be available, these often require centralized handling of samples, as well as processing and interpretation by specially trained staff. For clinical trials in an emergent infectious disease, however, a decentralized, sensitive rapid pointof-care testing approach is preferable, to allow for highvolume testing in a low-resource environment by minimally trained healthcare workers. Studies to validate diagnostic tests for determination of eligibility, as well as for the monitoring of an experimental treatment, should be planned under similar scrutiny as the treatment trial itself, as this biomarker-driven treatment approach may be developed in parallel with the experimental treatment as a companion diagnostic device, and may be subject to additional regulatory requirements [77]. Examples on how to design and implement a validation study for a novel diagnostic device in an outbreak setting include the study protocol investigating the sensitivity and specificity of the ReEBOVTM rapid diagnostic test of Ebola antigen, which was implemented in a multisite approach in West Africa [78].

Especially in the small trial environment, the selection of outcome should follow the methodological concept of validity, reliability, and the ability to discriminate between different disease states, as well as responsiveness to interventions and the sensitivity to detect meaningful change [74]. Depending on the scope of the trial, a pivotal trial aimed at regulatory approval will select different outcomes (namely, clinical outcomes on how patients "feel, function, or survive" per Food and Drug Administration regulation) than trials focused on intermediate outcomes, aiming at informing future trials rather than changing clinical practice. In diseases that are typically fatal, survival is one of the most relevant trial end points, as survival as outcome is objective, easy to measure, and not subject to bias [67]. Alternatively, time to progression can be used as outcome if the time point of progression can be clearly defined as event in a clinical trial. Many neurovirological trials will use biomarkers as outcomes. To qualify as a surrogate biomarker, the outcome (e.g., viral load) should be responsive to the treatment intervention and predict a clinical outcome. However, if biomarkers are not in the direct causal chain between disease etiology, treatment target and clinical outcome, the interpretation could become challenging. In early trial phases, biomarkers can be useful as proof-of-concept criterion for "go-no go" decisions.

\section{Novel Methodological Approaches and Trial Designs}

Clinical trials in neurovirology may have common challenges, including limited sample sizes, an emergency or intensive care setting, and regional and temporal outbreak scenarios, as well as settings in which established and rapidly deployable diagnostic tests are not yet available. As the imperative to conduct well-controlled trials to minimize bias often conflicts with these challenges, individual clinical trial designs should be tailored to the specific characteristics of a given neurovirological disease. Clinical trials in neurovirology should be appropriately controlled and blinded. If a "classic" design, such as an RCT using a placebo as a concurrent, parallel control group, is not feasible, other design options are available. In settings, where not all parameters are known at the outset of the trial to plan an a priori, "well-powered" experiment, novel trial designs can help answer questions of efficacy and safety, which are otherwise challenging to answer using a classic design. $N$-of-1 designs have been established to offer a "trial of therapy" to individual patients, and can be a powerful tool in the assessment of comparative effectiveness [79]. These designs are mostly useful in chronic conditions and can improve the certainty of a treatment decision at a single-patient level, with patients serving as their own controls. Patients undergo at least 2 treatment periods with experimental and control treatments in a double-blind fashion, optionally preceded by an open-label run-in phase to optimize the individual treatment regimen. In settings where a treatment is already widely being prescribed for off-label use, and a placebo-controlled trial would therefore face challenges during recruitment, the concept of pragmatic clinical trials, in which data obtained from electronic health records would be the basis for an analysis, could be a valuable approach [80]. As mentioned above, sequential and group sequential designs, as well as adaptive designs, allow for the "learning" of important trials 
parameters while a trial is already under way, making a rapid deployment of development programs in outbreak settings, in situations with limited sample sizes, as well as in scenarios where certain parameters are not yet known. Bayesian designs have been proposed for trials in the infectious disease setting such as Ebola [81], including trial design such as the platform trial, which allows the addition and removal of entire treatment arms throughout the study [73].

In summary, even in challenging environments of neurovirological diseases, where key components for large, "classic" placebo-controlled parallel-group RCTs are not available, alternative trial designs should be considered to preserve the imperative of a well-controlled clinical trial to answer a question on efficacy and safety of an experimental treatment in an unbiased and efficient way.

Box 1. Challenges in trial design for neurovirological diseases

- Selection of adequate controls, to ensure equipoise, and reduce bias.

- Availability of sufficient sample sizes, to avoid underpowered trials.

- Application of valid, reliable, and meaningful diagnostic tests and outcome measures.

- Efficient trial implementation in a regionally and/or temporally constrained setting such as outbreak scenarios, requiring concerted efforts among investigators, policy-makers, regulators, medical staff, and community.

Box 2. Trial design considerations to overcome challenges in neurovirological diseases

- Designing natural history cohort studies focusing on "clinical trial readiness", aiming at:

- describing the natural progression of the disease to inform future power calculations

- developing and selecting diagnostic tests, biomarkers, and clinical outcome measures

- creating a natural history cohort group as control for future clinical trials

- assessing feasibility and refine procedures for future clinical trials (e.g., recruitment, retention, tests, etc.).

- Adequate clinical trial controlling may be achieved via:

- randomization to placebo, active control, no-treatment control, or dosecomparison control

- when randomization is not feasible, rigorous external controlling via historical control, or baseline control

- blinding towards the treatment allocation.

- Examples of innovative trial designs:

- cluster-randomized trials

- sequential trials

- adaptive trials

- platform trials

- N-of-1 trials

- pragmatic clinical trials.

\section{References}

1. Boston Interhospital Virus Study Group and the NIAID-sponsored Cooperative Antiviral Clinical Study. Failure of high dose 5-iodo2'-deoxyuridine in the therapy of herpes simplex virus encephalitis. Evidence of unacceptable toxicity. N Engl J Med 1975;292:599603.

2. Whitley RJ, Soong SJ, Dolin R, Galasso GJ, Ch'ien LT, Alford CA. Adenine arabinoside therapy of biopsy-proved herpes simplex encephalitis. National Institute of Allergy and Infectious Diseases collaborative antiviral study. N Engl J Med 1977;297:289-294.

3. Whitley RJ, Alford CA, Hirsch MS, et al. Vidarabine versus acyclovir therapy in herpes simplex encephalitis. N Engl J Med 1986;314:144-149.

4. Skoldenberg B, Forsgren M, Alestig K, et al. Acyclovir versus vidarabine in herpes simplex encephalitis. Randomised multicentre study in consecutive Swedish patients. Lancet 1984;2:707-711.

5. Whitley RJ, Cobbs CG, Alford CA, Jr., et al. Diseases that mimic herpes simplex encephalitis. Diagnosis, presentation, and outcome. NIAD Collaborative Antiviral Study Group. JAMA 1989;262:234239.

6. Aurelius E, Johansson B, Skoldenberg B, Staland A, Forsgren M. Rapid diagnosis of herpes simplex encephalitis by nested polymerase chain reaction assay of cerebrospinal fluid. Lancet 1991;337: 189-192.

7. Lakeman FD, Whitley RJ. Diagnosis of herpes simplex encephalitis: Application of polymerase chain reaction to cerebrospinal fluid from brain-biopsied patients and correlation with disease. J Infect Dis $1995 ; 171: 857-863$.

8. Solomon T, Michael BD, Smith PE, et al. Management of suspected viral encephalitis in adults-Association of British Neurologists and British Infection Association National Guidelines. J Infect 2012;64:347-373.

9. Steiner I, Schmutzhard E, Sellner J, et al. EFNS-ENS guidelines for the use of PCR technology for the diagnosis of infections of the nervous system. Eur J Neurol 2012;19:1278-1291.

10. Whitley RJ, Gnann JW. Viral encephalitis: familiar infections and emerging pathogens. Lancet 2002;359:507-513.

11. Kennedy PG, Steiner I. Recent issues in herpes simplex encephalitis. J Neurovirol 2013;19:346-350.

12. Snider WD, Simpson DM, Nielsen S, Gold JWM, Metroka CE, Posner JB. Neurological complications of acquired immune deficiency syndrome: analysis of 50 patients. Ann Neurol 1983;14:403418.

13. Navia BA, Jordan BD, Price RW. The AIDS dementia complex: I. Clinical features. Ann Neurol 1986;19:517-524.

14. Navia BA, Cho ES, Petito CK, Price RW. The AIDS dementia complex: II. Neuropathology. Ann Neurol 1986;19:525-535.

15. Schmitt FA, Bigley JW, McKinnis R, et al. Neuropsychological outcome of zidovudine (AZT) treatment of patients with AIDS and AIDS-related complex. N Engl J Med 1988;319:1573-1578.

16. Sidtis JJ, Gatsonis C, Price RW, et al. Zidovudine treatment of the AIDS dementia complex: results of a placebo-controlled trial. Ann Neurol 1993;33:343-349.

17. Sidtis JJ, Dafni U, Slasor P, et al. Stable neurological function in subjects treated with 2'3'-dideoxyinosine. J Neurovirol 1997;3:233240.

18. Clifford DB, Evans S, Yang Y, et al. Impact on efavirenz on neuropsychological performance and symptoms in HIV-infected individuals. Ann Intern Med 2005;143:714-721.

19. Price RW, Yiannoutsos CT, Clifford DB, et al. Neurological outcomes in late HIV infection: adverse impact of neurological impairment on survival and protective effect of antiviral therapy. AIDS Clinical Trial Group and Neurological AIDS Research Consortium study team. Aids 1999;13:1677-1685. 
20. Ellis RJ, Hsia K, Spector SA, et al. Cerebrospinal fluid human immunodeficiency virus Type 1 RNA levels are elevated in neurocognitively impaired individuals with acquired immunodeficiency syndrome. Ann Neurol 1997;42:679-688.

21. McArthur JC, McClernon DR, Cronin MF, et al. Relationship between human immunodeficiency virus-associated dementia and viral load in cerebrospinal fluid and brain. Ann Neurol 1997;42:689698.

22. Burdo TH, Weiffenbach A, Woods SP, Letendre S, Ellis RJ, Williams KC. Elevated sCD163 in plasma but not cerebrospinal fluid is a marker of neurocognitive impairment in HIV infection. Aids 2013;27:1387-1395.

23. Valcour VG, Ananworanich J, Agsalda M, et al. HIV DNA reservoir increases risk for cognitive disorders in cART-naive patients. PLOS ONE 2013;8:e70164

24. Peluso MJ, Ferretti F, Peterson J, et al. Cerebrospinal fluid HIV escape associated with progressive neurologic dysfunction in patients on antiretroviral therapy with well controlled plasma viral load. Aids 2012;26:1765-1774.

25. Dahl V, Peterson J, Fuchs D, Gisslen M, Palmer S, Price RW. Low levels of HIV-1 RNA detected in the cerebrospinal fluid after up to 10 years of suppressive therapy are associated with local immune activation. Aids 2014;28:2251-2258.

26. Yilmaz A, Yiannoutsos CT, Fuchs D, et al. Cerebrospinal fluid neopterin decay characteristics after initiation of antiretroviral therapy. J Neuroinflammation 2013;10:62.

27. Letendre S, Marquie-Beck J, Capparelli E, et al. Validation of the CNS penetration-effectiveness rank for quantifying antiretroviral penetration into the central nervous system. Arch Neurol 2008;65: 65-70.

28. Ellis RJ, Letendre S, Vaida F, et al. Randomized trial of central nervous system-targeted antiretrovirals for HIVassociated neurocognitive disorder. Clin Infect Dis 2014;58: 1015-1022.

29. Lanier ER, Sturge G, McClernon D, et al. HIV-1 reverse transcriptase sequence in plasma and cerebrospinal fluid of patients with AIDS dementia complex treated with Abacavir. Aids 2001;15: 747-751.

30. Brew BJ, Halman M, Catalan J, et al. Factors in AIDS dementia complex trial design: results and lessons from the abacavir trial. PLOS Clin Trials 2007;2:e13.

31. Yilmaz A, Verhofstede C, D'Avolio A, et al. Treatment intensification has no effect on the HIV-1 central nervous system infection in patients on suppressive antiretroviral therapy. J Acquir Immune Defic Syndr 2010;55:590-596.

32. Gates TM, Cysique LA, Siefried KJ, Chaganti J, Moffat KJ, Brew BJ. Maraviroc-intensified combined antiretroviral therapy improves cognition in virally suppressed HIV-associated neurocognitive disorder. Aids 2016;30:591-600.

33. Underwood J, Robertson KR, Winston A. Could antiretroviral neurotoxicity play a role in the pathogenesis of cognitive impairment in treated HIV disease? Aids 2015;29:253-261.

34. Marra CM, Zhao Y, Clifford DB, et al. Impact of combination antiretroviral therapy on cerebrospinal fluid HIV RNA and neurocognitive performance. Aids 2009;23:1359-1366.

35. Legarth RA, Ahlstrom MG, Kronborg G, et al. Long-term mortality in HIV-infected individuals 50 years or older: a nationwide, population-based cohort study. J Acquir Immune Defic Syndr 2016;71:213-218.

36. Samji H, Cescon A, Hogg RS, et al. Closing the gap: increases in life expectancy among treated HIV-positive individuals in the United States and Canada. PLOS ONE 2013;8:e81355.

37. Cole MA, Margolick JB, Cox C, et al. Longitudinally preserved psychomotor performance in long-term asymptomatic HIVinfected individuals. Neurology 2007;69:2213-2220.
38. Heaton RK, Franklin DR, Jr., Deutsch R, et al. Neurocognitive change in the era of HIV combination antiretroviral therapy: the longitudinal CHARTER study. Clin Infect Dis 2015;60:473-480.

39. Young AC, Yiannoutsos CT, Hegde M, et al. Cerebral metabolite changes prior to and after antiretroviral therapy in primary HIV infection. Neurology 2014;83:1592-1600.

40. Peluso MJ, Meyerhoff DJ, Price RW, et al. Cerebrospinal fluid and neuroimaging biomarker abnormalities suggest early neurological injury in a subset of individuals during primary HIV infection. J Infect Dis 2013;207:1703-1712.

41. Heseltine PN, Goodkin K, Atkinson JH, et al. Randomized doubleblind placebo-controlled trial of peptide T for HIV-associated cognitive impairment. Arch Neurol 1998;55:41-51.

42. Anon. Safety and tolerability of the antioxidant OPC-14,117 in HIV associated cognitive impairment. Neurology 1997;49:142-146.

43. Anon. A randomized, double-blind, placebo-controlled trial of deprenyl and thioctic acid in human immunodeficiency virusassociated cognitive impairment. Neurology 1998;50:645-651.

44. Navia BA, Dafni U, Simpson D, et al. A phase I/II trial of nimodipine for HIV-related neurologic complications. Neurology 1998;51:221-228.

45. Schifitto G, Sacktor N, Marder K, et al. Randomized, placebocontrolled trial of the PAF antagonist lexipafant in HIV-associated cognitive impairment. Neurology 1999;53:391-396.

46. Simioni S, Cavassini M, Annoni JM, et al. Rivastigmine for HIVassociated neurocognitive disorders: a randomized crossover pilot study. Neurology 2013;80:553-560.

47. Sacktor N, Miyahara S, Deng L, et al. Minocycline treatment for HAND: results from a multicenter trial. 18th Conference on Retroviruses and Opportunistic Infections 2011:229.

48. Berger JR, Pall L, Lanska D, Whiteman M. Progressive multifocal leukoencephalopathy in patients with HIV infection. J Neurovirol 1998;4:59-68.

49. Hall CD, Dafni U, Simpson D, et al. Failure of cytarabine in progressive multifocal leukoencephalopathy associated with human immunodeficiency virus infection. N Engl J Med 1998;338:1345-1351.

50. Royal W, 3rd, Dupont B, McGuire D, et al. Topotecan in the treatment of acquired immunodeficiency syndrome-related progressive multifocal leukoencephalopathy. J Neurovirol 2003;9:411-419.

51. Marra CM, Rajicic N, Barker DE, et al. AACTG 363: A pilot study of cidofovir for progressive multifocal leukoencephalopathy (PML) in AIDS. J Neurovirol 2003;9:30-31.

52. De Luca A, Ammassari A, Pezzotti P, et al. Cidofovir in addition to antiretroviral treatment is not effective for AIDS-associated progressive multifocal leukoencephalopathy: a multicohort analysis. Aids 2008;22:1759-1767.

53. Gasnault J, Costagliola D, Hendel-Chavez H, et al. Improved survival of HIV-1-infected patients with progressive multifocal leukoencephalopathy receiving early 5 -drug combination antiretroviral therapy. PLOS ONE 2011;6:e20967.

54. Clifford DB, Nath A, Cinque P, et al. A study of mefloquine treatment for progressive multifocal leukoencephalopathy: results and exploration of predictors of PML outcomes. J Neurovirol 2013;19: 351-358.

55. Brickelmaier M, Lugovskoy A, Kartikeyan R, et al. Identification and characterization of mefloquine efficacy against $\mathrm{JC}$ virus in vitro. Antimicrob Agents Chemother 2009;53:1840-1849.

56. Clifford DB, Yiannoutsos C, Glicksman M, et al. HAART improves prognosis in HIV-associated progressive multifocal leukoencephalopathy. Neurology 1999;52:623-625.

57. Yousry TA, Major EO, Ryschkewitsch C, et al. Evaluation of patients treated with natalizumab for progressive multifocal leukoencephalopathy. N Engl J Med 2006;354:924-933.

58. Kleinschmidt-DeMasters BK, Tyler KL. Progressive multifocal leukoencephalopathy complicating treatment with natalizumab 
and interferon beta-1a for multiple sclerosis. N Engl J Med 2005;353:369-374.

59. Langer-Gould A, Atlas SW, Pelletier D. Progressive multifocal leukoencephalopathy, natalizumab, and multiple sclerosis. N Engl J Med 2005;353:1745-1746.

60. Van Assche G, Van Ranst M, Sciot R, et al. Progressive multifocal leukoencephalopathy after natalizumab therapy for Crohn's disease. N Engl J Med 2005;353:362-368.

61. Alstadhaug KB, Croughs T, Henriksen S, et al. Treatment of progressive multifocal leukoencephalopathy with interleukin 7. JAMA Neurol 2014;71:1030-1035.

62. Sospedra M, Schippling S, Yousef S, et al. Treating progressive multifocal leukoencephalopathy with interleukin 7 and vaccination with JC virus capsid protein VP1. Clin Infect Dis 2014;59:1588-1592.

63. Berger JR, Aksamit AJ, Clifford DB, et al. PML diagnostic criteria: Consensus statement from the AAN Neuroinfectious Disease Section. Neurology 2013;80:1430-1438.

64. Mateen FJ, Muralidharan R, Carone M, et al. Progressive multifocal leukoencephalopathy in transplant recipients. Ann Neurol 2011;70: 305-322.

65. Gehan EA, Freireich EJ. Non-randomized controls in cancer clinical trials. N Engl J Med 1974;290:198-203.

66. Kraemer HC, Mintz J, Noda A, Tinklenberg J, Yesavage JA. Caution regarding the use of pilot studies to guide power calculations for study proposals. Arch Gen Psychiatry 2006;63:484-489.

67. Byar DP, Schoenfeld DA, Green SB, et al. Design considerations for AIDS trials. N Engl J Med 1990;323:1343-1348.

68. Pocock SJ. The combination of randomized and historical controls in clinical trials. J Chronic Dis 1976;29:175-188.

69. Fleming TR, Ellenberg SS. Evaluating interventions for Ebola: the need for randomized trials. Clin Trials 2016;13:6-9.

70. Emanuel EJ, Wendler D, Killen J, Grady C. What makes clinical research in developing countries ethical? The benchmarks of ethical research. J Infect Dis 2004;189:930-937.

71. Lane HC, Marston HD, Fauci AS. Conducting clinical trials in outbreak settings: points to consider. Clin Trials 2016;13:92-95

72. Check DK, Weinfurt KP, Dombeck CB, Kramer JM, Flynn KE. Use of central institutional review boards for multicenter clinical trials in the United States: a review of the literature. Clin Trials 2013;10:560-567.

73. Berry SM, Petzold EA, Dull P, et al. A response adaptive randomization platform trial for efficient evaluation of Ebola virus treatments: a model for pandemic response. Clin Trials 2016;13:22-30.

74. Evans CH, Ildstad ST. Small Clinical Trials: Issues and Challenges. Washington, DC: Institute of Medicine; 2001.

75. Cheung YK. Sample size formulae for the Bayesian continual reassessment method. Clin Trials 2013;10:852-861.

76. Kairalla JA, Coffey CS, Thomann MA, Muller KE. Adaptive trial designs: a review of barriers and opportunities. Trials 2012;13:145.

77. In Vitro Companion Diagnostic Devices - Guidance for Industry and Food and Drug Administration Staff. U.S. Food and Drug Administration, http://www.fda.gov/downloads/medicaldevices/ deviceregulationandguidance/guidancedocuments/ucm 262327. pdf. 2014.

78. Schieffelin J, Moses LM, Shaffer J, Goba A, Grant DS. Clinical validation trial of a diagnostic for Ebola Zaire antigen detection: design rationale and challenges to implementation. Clin Trials 2016;13:66-72.

79. Duan N, Kravitz RL, Schmid CH. Single-patient (n-of-1) trials: a pragmatic clinical decision methodology for patient-centered comparative effectiveness research. J Clin Epidemiol 2013;66(8 Suppl.):S21-S28.

80. Califf RM, Sugarman J. Exploring the ethical and regulatory issues in pragmatic clinical trials. Clin Trials 2015;12:436-441.

81. Proschan MA, Dodd LE, Price D. Statistical considerations for a trial of Ebola virus disease therapeutics. Clin Trials 2016;13:39-48.

82. Yiannoutsos CT, Major EO, Curfman B, et al. Relation of JC virus DNA in the cerebrospinal fluid to survival in acquired immunodeficiency syndrome patients with biopsy-proven progressive multifocal leukoencephalopathy. Ann Neurol 1999;45:816-821.

83. Marra CM, Lockhart D, Zunt JR, Perrin M, Coombs RW, Collier AC. Changes in CSF and plasma HIV-1 RNA and cognition after starting potent antiretroviral therapy. Neurology 2003;60:13881390. 